
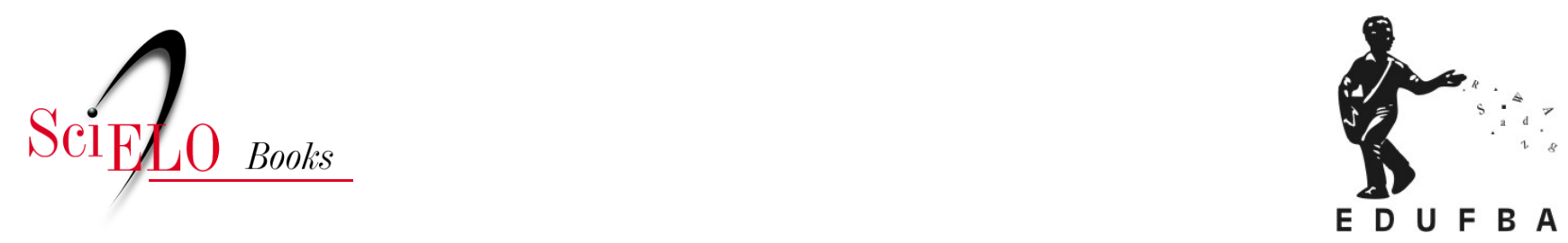

\title{
Focalização sem foco \\ fragmentação dos primeiros programas sociais de transferência de renda focalizados
}

José Carlos da Exaltação Torres

\section{SciELO Books / SciELO Livros / SciELO Libros}

TORRES, J.C.E. Focalização sem foco: fragmentação dos primeiros programas sociais de transferência de renda focalizados. In: Cadastro Único: tecnologia de reclassificação social [online]. Salvador: EDUFBA, 2016, pp. 99-113. ISBN: 978-65-5630-011-5. https://doi.org/10.7476/9786556300115.0008.

International license.

Todo o conteúdo deste trabalho, exceto quando houver ressalva, é publicado sob a licença Creative Commons Atribição $\underline{4.0}$.

Todo el contenido de esta obra, excepto donde se indique lo contrario, está bajo licencia de la licencia Creative Commons Reconocimento 4.0. 


\section{FOCALIZAÇÃO SEM FOCO: FRAGMENTAÇÃO DOS PRIMEIROS PROGRAMAS SOCIAIS DE TRANSFERÊNCIA DE RENDA FOCALIZADOS}

Este capítulo faz uma análise sintética sobre os programas focalizados de transferência de renda, implementados pelo governo federal brasileiro antes da criação do Cadastro Único e mesmo durante os primeiros meses de implantação deste cadastro, dando destaque à dinâmica e aos critérios utilizados para a seleção de beneficiários e identificando os principais problemas enfrentados nesse processo. A análise demonstra que, desde meados da década de 1990, o governo tem operado com PTR com condicionalidades, focalizados nas famílias de "baixa renda", ou seja, a parcela da população cuja renda per capta mensal não ultrapassa meio salário mínimo oficial. Em função disso, entre 1996 e 2002, criaram-se o PETI (Programa de Erradicação do Trabalho Infantil) (1996); o Bolsa Escola - Programa Nacional de Renda Mínima vinculado à educação (2001) -, o Bolsa Alimentação - Programa Nacional de Renda Mínima vinculado à saúde (2001) - e o Auxílio Gás (2002). De uma forma geral, observa-se que a implantação desses programas exigiu a criação de bases de dados centralizadas e específicas, fazendo com que cada programa, à exceção do Auxílio Gás - que será analisado mais à frente (na segunda parte do livro) -, tivesse a sua própria fonte de informações, embora em essência todos eles fossem destinados a um mesmo público, a população designada como sendo de "baixa renda". Contudo, os dados coletados no processo de cadastramento não correspondiam à família integralmente, mas apenas aos membros que atendiam aos critérios estabe- 
lecidos por cada programa, o que limitava bastante os usos das informações geradas a partir deles.

\section{PETI - PROGRAMA DE ERRADICAÇÃO DO TRABALHO INFANTIL ${ }^{20}$}

O PETI foi um programa implantado gradualmente e de forma bastante diversificada no Brasil. Cumpriu uma etapa da realização do, assim chamado, "Compromisso pela Criança”, celebrado entre o Governo Federal, os governos estaduais e instituições da sociedade civil, dentre as quais representações do empresariado brasileiro. O programa se desenvolveu sob influência da Organização Internacional do Trabalho (OIT), instituição coordenadora do Programa Internacional para Eliminação do Trabalho Infantil (IPEC), direcionado a um grupo de países do qual o Brasil faz parte desde o início da década de 1990. (BAHIA, [199-?], BRASIL, 1998; CAMPOS, 1998)

Em 1996, ano em que foi assinado o Termo desse Compromisso - no qual constava, dentre as atribuições dos governos, "promover e apoiar iniciativas de emprego e geração de renda" e estimular "a permanência e o sucesso escolar das crianças e adolescentes" desenvolvendo atividades laborais de risco (CAMPOS, 1998, p. 5) -, decidiu-se pela realização de um trabalho conjunto, direcionado às áreas apontadas no diagnóstico sobre o trabalho infantil no país, elaborado pelo Fórum Nacional de Prevenção e Erradicação do Trabalho Infantil, instituição vinculada ao Comitê Diretivo do IPEC, priorizando inicialmente áreas onde a mão de obra infantil era utilizada em grande escala, e cujo indicador de desenvolvimento social estivesse abaixo da média nacional. E assim, em 1996, o PETI foi implantado como um projeto piloto na área das carvoarias do Mato Grosso do Sul e, em 1997, foi ampliado para os canaviais de Pernambuco e para a região do sisal e das pedreiras no estado da Bahia.

Sendo fruto da articulação entre instituições públicas e privadas, o PETI condicionou-se, desde o início, à natureza dessas relações e contou com as experiências já desenvolvidas em cada região contra o trabalho in-

20 O material principal do qual nos servimos para a descrição do PETI foi o Relatório de Avaliação do Programa, elaborado pelo Instituto de Estudos Especiais da Pontifícia Universidade Católica (PUC) de São Paulo, sob a coordenação da Prof ${ }^{a}$ Dr $^{a}$ Marta Silva Campos, referente ao período 1996-1997. 
fantil, tendo sido estabelecido, inclusive, como critério de seleção das áreas para a sua implantação, a existência de organização e mobilização social que pudesse ser empregada para os fins do Programa. Sua implantação pressupunha também, dentre outros aspectos, a elaboração de um diagnóstico, de caráter quantitativo e qualitativo, da situação de trabalho infantil na região selecionada, o que tornava indispensável essa articulação entre amplos setores da sociedade e as esferas governamentais. Aliás, o PETI sustenta como uma de suas características a realização de articulação ampla também em nível de governo, constituindo-se numa "ação interministerial" entre as áreas da Previdência e Assistência, do Trabalho, Educação e Desporto, Saúde, Justiça e Casa Civil. (CAMPOS, 1998) Os critérios de elegibilidade de beneficiários pautavam-se, além do tipo de relação com o trabalho, na faixa etária e na situação domiciliar, considerando-se a relevância do trabalho infantil para a composição da renda e sobrevivência familiar. A “Bolsa Criança Cidadã”, instituída pelo Programa, viria, neste sentido, compensar a necessária desvinculação das crianças do processo de geração de renda da família.

Em Mato Grosso do Sul, ${ }^{21}$ estado selecionado para a realização da primeira experiência do PETI, o projeto que deu existência ao Programa foi elaborado pela Fundação de Promoção Social de Mato Grosso do Sul (PROMOSUL) e pelo Escritório Regional da Secretaria de Assistência Social. A sua execução, dada a partir de maio de 1996,22 uniu a PROMOSUL e a Secretaria de Educação daquele estado, além das secretarias municipais de Assistência Social, Educação e Saúde. Os parâmetros que orientaram as metas estabelecidas no Programa, bem como o cadastramento dos potenciais beneficiários, consistiam de dados referentes ao perfil das carvoarias e das famílias de algumas localidades e à situação na educação e no trabalho, concernentes às crianças e aos adolescentes. Aos municípios, coube a tarefa de cadastrar as famílias beneficiárias e repassar-lhes as bolsas, definidas em $\mathrm{R} \$ 50$, oo por criança cadastrada.

Em Pernambuco, atribui-se à pesquisa realizada pelo Centro Josué de Castro, entre 1992 e 1993, a referência principal do movimento de combate

21 Em Mato Grosso do Sul, a Bolsa Criança Cidadã recebeu o nome de "Vale Cidadania".

22 Não está claro para nós a cronologia de concepção do PETI, uma vez que o Termo de Compromisso que lhe confere existência é de setembro de 1996 e o estado do Mato Grosso do Sul já o implementara desde o mês de maio. Ao que parece, considerando que o Fórum Nacional é de 1994, em setembro de 1996 o Compromisso foi apenas ratificado, o que pode ser exemplificado pelo fato de o Brasil ser vinculado ao IPEC desde o início da década. 
ao trabalho infantil. A articulação entre governo e sociedade civil, porém, data de abril de 1996, e a concepção do programa deve-se aos resultados de eventos realizados no segundo semestre daquele ano, ${ }^{23}$ tendo a sua implantação ocorrido em janeiro de 1997. A Secretaria de Trabalho e Ação Social do estado desenvolveu o "Cadastro Geral dos Municípios”, para identificar as crianças trabalhando na atividade canavieira na zona rural, bem como a situação dessa população em relação à escolaridade. $\mathrm{O}$ cadastramento ficou ao encargo das prefeituras, com o apoio dos sindicatos das localidades visadas. Pelos critérios estabelecidos, permitiu-se a inclusão de crianças que não trabalhavam nas atividades em questão, mas cujas famílias trabalhavam, inaugurando, assim, o caráter preventivo do Programa. O valor da bolsa foi definido em $\mathrm{R} \$ 50,00$, mas cada família podia ter acesso ao máximo de três bolsas, sendo que sua distribuição era escalonada da seguinte forma: uma bolsa para dois filhos, duas bolsas para três ou quatro filhos e três bolsas para cinco filhos ou mais, atendendo ainda ao critério da faixa etária entre sete e quatorze anos. Campos (1998, p. 61) aponta para o acúmulo de trabalho sobre as equipes municipais para o "cadastramento e inscrição de crianças e adolescentes, a seleção e capacitação de monitores e a construção e adequação de espaços".

$\mathrm{Na}$ Bahia, as mobilizações contra o trabalho infantil nas atividades do sisal datam da década de 1960, envolvendo a Igreja e instituições sociais privadas, motivadas pela periculosidade, pela insalubridade e por todos os danos causados por essa atividade. Já em meados da década de 1990, o Ministério do Trabalho instalou o "Núcleo Estadual de Combate ao Trabalho Infantil”, com o fito de realizar inspeção sobre a situação, cujos resultados puseram o estado na relação prioritária do Fórum Nacional para a instalação do PETI. (CAMPOS, 1998) No segundo semestre de 1996, foi instituída no estado uma "Comissão Interinstitucional" visando à elaboração do seu projeto para erradicação do trabalho infantil. Essa Comissão promoveu uma "Oficina de Planejamento" para a construção de um "Plano de Ações Integradas", no qual foram traçados os princípios do que viria a ser o PETI no estado.

23 "Seminário Estadual para a Eliminação do Trabalho Infantil e Proteção ao Adolescente", em agosto, e "Oficina de Trabalho sobre "Estratégias de Política Pública de Atenção a Segmentos Excluídos”, em dezembro. (CAMPOS, 1998, p. 38) 
A Secretaria do Trabalho e Assistência Social (SETRAS), instituição responsável pelo programa no estado, firmou convênio com o Centro de Recursos Humanos da Universidade Federal da Bahia (CRH-UFBA) para o cadastramento das famílias a serem beneficiadas pelo PETI. Os cadastros, em verdade, compuseram uma pesquisa mais ampla realizada pelo Centro: a pesquisa "Criança Cidadã". "Foram quantificadas a população infanto-juvenil, a sua parcela trabalhadora no sisal, em outras atividades, além da matriculada em escolas”. (CAMPOS, 1998, p. 74) Junto a outros levantamentos realizados no estado, os resultados da pesquisa "constituíram o Cadastro de Informações Municipais que concentra todas as informações do Programa”. (CAMPOS, 1998, p. 74)

Os critérios de elegibilidade foram flexionados para permitir que também as crianças e adolescentes trabalhadores das pedreiras - atividade correlata ao sisal no emprego de mão de obra infantil - fossem incluídas. Desde o início foram adotados critérios preventivos para a seleção, pelo que admitiu-se a inclusão de crianças que não trabalhavam diretamente nessas atividades, mas cuja família o fazia. De todo modo, isso teve seu limite dado pelo impedimento de inclusão de crianças cujo risco social estava apenas no fato de residirem na região e cujas famílias se encontravam em situação de carência. Posteriormente, o nível de renda foi incorporado enquanto critério seletivo. Quanto à bolsa paga às famílias, o valor foi definido em $\mathrm{R} \$$ 25, oo. Na estrutura organizacional de operacionalização do Programa, foi instituído um “Grupo Gestor” para o seu monitoramento, com prerrogativa para autorizar o pagamento de bolsas, bem como para a suspensão ou exclusão de beneficiários, mediante controle sobre o cumprimento das condicionalidades estabelecidas, no tocante à frequência escolar.

Esses dados apresentam uma caracterização geral sobre os princípios do PETI em seu período inicial, quando se observa que não havia critérios uniformes para a implementação do Programa, especialmente para a seleção de seus beneficiários, situação sobre a qual, com o passar do tempo, serão emitidas normas corretivas. Faz-se necessário destacar, nesse aspecto, as características desse programa em relação ao processo de cadastramento e seleção de beneficiários. A Portaria n.ำ 2.917, de 12 de setembro de 2000, ao estabelecer as diretrizes do PETI, indica que o Programa é destinado prioritariamente a "famílias com renda per capta de até I/2 salário mínimo". (BRASIL, 200o, Anexo, item 3) O cadastro dessas famílias deve obedecer ao modelo formulado pela Secretaria de Estado de Assistência Social (SEAS), 
órgão no qual se localizará a base de dados nacional do programa, o "Sistema Nacional de Informações Gerenciais”. A relação do governo federal se dá diretamente com a esfera estadual, e não a municipal; assim, é o órgão gestor da Assistência Social no estado que se responsabiliza por validar e encaminhar ao Governo Federal (SEAS) os cadastros dos beneficiários e por realizar o diagnóstico socioeconômico das áreas priorizadas. (BRASIL, 200oAnexo, itens 5.6- 6.2) De todo modo, é o município o responsável por cadastrar as famílias beneficiárias, inclusive inserindo "critérios complementares" no processo de seleção, viabilizando assim o "Cadastro de Informações Municipais”, que alimentará o Sistema Nacional. Mas é à instância estadual que seus dados serão remetidos, e é a esse nível que seus eventuais problemas serão dirimidos.

As iniciativas em favor da normatização do PETI, porém, parecem não ter alcançado um nível satisfatório de correção dos problemas gerados em sua implementação. É o que se verifica, por exemplo, no resultado de uma auditoria do TCU realizada entre setembro e outubro de 2001 sobre o Programa. Em seu relatório, o Tribunal apontou o que seriam os principais óbices ao alcance dos objetivos do PETI, dentre os quais estavam, de um lado, a inexistência de dados precisos sobre o número de crianças que correspondiam ao perfil do Programa e, de outro, a heterogeneidade dos mecanismos de inserção de beneficiários entre estados e regiões do país.

A auditoria verificou que, dos municípios contemplados pelo PETI em todo o Território Nacional, 55\% não dispunham de dados sobre o público -alvo do Programa, e dos que possuíam (41\%), a maioria se pautava apenas em estimativas pouco consistentes, configurando uma séria dificuldade das administrações locais para a construção de dados confiáveis à execução do Programa e gerando, além disso, um outro nível de dificuldade: o de aferir os resultados do Programa, pela falta de um parâmetro definido. As poucas experiências tidas como bem sucedidas são apresentadas como casos isolados, a exemplo do ocorrido no estado da Bahia, como relatado acima. Assim, já nesse relatório do TCU, aponta-se para a necessidade premente de criação de um cadastro consistente e uniforme sobre o público-alvo do PETI.

Com o fito de prevenir as distorções que se dão na aplicação do Programa, dada pela baixa clareza sobre seus objetivos e, sobretudo, pela precariedade de estatísticas para a sua execução e acompanhamento, o TCU sugere ao governo a implementação de ações para uniformização da me- 
todologia de identificação e dos critérios de inclusão das famílias beneficiárias e a construção de um cadastro para identificação e quantificação das crianças em situação de trabalho infantil. Coincidentemente (ou não) esse é o período em que começa a vigorar o Cadastro Único do Governo Federal, do qual o PETI, por força da lei, deverá fazer uso. Assim, em resposta às recomendações feitas pelo Tribunal de Contas, em versão preliminar do Relatório enviada à SEAS, o Gestor do Programa afirma que o Cadastro Único deverá corrigir os problemas de identificação e quantificação do público-alvo. Em conta disso, o TCU expressa sua expectativa sobre o novo cadastro, enquanto instrumento de racionalização e unificação dos bancos de dados concernentes aos programas sociais federais, mas ressalta que os resultados desse cadastro condicionar-se-ão às formas em que se dará a coleta de dados e ao nível de controle social sobre esse processo. (BRASIL, 2001k)

\section{BOLSA ESCOLA - PROGRAMA NACIONAL DE RENDA MÍNIMA VINCULADO À EDUCAÇÃO ${ }^{24}$}

O Programa Bolsa Escola foi criado em 13 de fevereiro de 2001, através da Medida Provisória n.. 2.140/2001, convalidada pela Lei n.ำ 10.219, de 11 de abril de 2001, sob a gestão do Ministério da Educação. Esse é um programa que estabelece relação direta entre União e Município, constituindo-se em "instrumento de participação financeira da União em programas municipais de garantia de renda mínima associados a ações socioeducativas" (BRASIL, 2001h, Art. $1^{\circ}$, § $1^{\circ}$ ) e cuja implementação ancora-se na formação de um Cadastro Nacional de Beneficiários. A inclusão dos municípios no programa dar-se-ia mediante assinatura de Termo de Adesão. (BRASIL, $2001 h)^{25}$

Na criação do Bolsa Escola, instituiu-se a figura do "agente operador", designação que encerra um conjunto de atribuições delegadas à CEF:

\footnotetext{
24 A Medida Provisória n. ${ }^{\circ}$ 2.140/2001, que cria o programa Bolsa Escola, e a Lei n. ${ }^{\circ}$ 10.219/2001, que a convalida o nominam como Programa Nacional de Renda Mínima "vinculada" à educação, enquanto no Decreto n. ${ }^{\circ} 3.823 / 2001$, que aprova o seu Regulamento, o nome apresentado é Programa Nacional de Renda Mínima “vinculado" à educação. Por uma questão exclusivamente de sintaxe, aqui será considerada a última alternativa.
}

Ver Art. $2^{\circ}$, inciso I; Art. $5^{\circ}$, inciso I. 
I - o fornecimento da infraestrutura necessária à organização e manutenção do cadastro nacional de beneficiários;

II - o desenvolvimento dos sistemas de processamento de dados;

III - a organização e operação da logística de pagamento dos benefícios; e

IV - a elaboração dos relatórios necessários ao acompanhamento, à avaliação e à auditoria da execução do programa por parte do Ministério da Educação. (BRASIL, 2001h, Art. $1^{\circ},{ } 4_{4}^{\circ}$ )

Observa-se que, de forma semelhante ao que se buscou fazer no PETI, o Bolsa Escola traz já de início a ideia de uma base de dados centralizada, um cadastro específico para os beneficiários do programa, agora, porém, inovado com um sistema externo de processamento de dados. À CEF cabe criar esse novo sistema, operá-lo e a partir dele definir a "logística de pagamento dos benefícios". O programa é destinado às famílias (não aos indivíduos), e a seleção dessas famílias obedecerá a um corte de renda a ser definido pelo Governo Federal, considerando que tenham em sua composição "crianças com idade entre seis e quinze anos, matriculadas em estabelecimentos de ensino fundamental regular, com frequência escolar igual ou superior a oitenta e cinco por cento". (BRASIL, 2001h, Art. $2^{\circ}$, inciso II) Neste ponto, explicita-se a vinculação à educação, que vem não como um aditivo do programa, mas como uma contraparte das famílias beneficiárias.

Quanto aos valores pagos, o Bolsa Escola é bem mais modesto que o PETI, estipulando um valor mensal de $\mathrm{R} \$ 15$, oo por criança (entre seis e 15 anos), limitando-se a três crianças por família, pelo que a "bolsa" pode alcançar o valor máximo de $\mathrm{R} \$ 45$, oo por mês. Esse dinheiro seria repassado diretamente às famílias, tendo como titular prioritário as mães das crianças beneficiárias ou responsável equivalente. (BRASIL, 2001h, Art. $4^{\circ}$, caput e, $\S 2^{\circ}$ ) Para fins de conceituação, definiu-se família como "a unidade nuclear, eventualmente ampliada por outros indivíduos que com ela possuam laços de parentesco, que forme um grupo doméstico, vivendo sob o mesmo teto e mantendo sua economia pela contribuição de seus membros". (BRASIL, 20orh, Art. $\left.4^{\circ}, \S_{1} 1^{\circ}\right)$ Vale ressaltar ainda que a inclusão no Programa Bolsa Escola era vedada aos beneficiários do PETI (BRASIL, 2001h, Art. $7^{\circ}$ ), o que sugere tratar-se de um mesmo público, além de certa similaridade das finalidades dos dois programas.

O Bolsa Escola era submetido ao acompanhamento de um conselho de controle social, composto por membros do poder público e da socie- 
dade civil. (BRASIL, 2001h Art. $2^{\circ}$, inciso IV) Dentre as suas atribuições, esse conselho deveria aprovar a relação das famílias cadastradas pelo Município para receberem o benefício. (BRASIL, 2001h, Art. 8o, inciso II). Além disso, os cadastros estariam sujeitos à compatibilização periódica por parte do Ministério da Educação, em referência aos indicadores econômicos e sociais dos seus respectivos municípios (BRASIL, 2001h Art. $5^{\circ}$, § $3^{\circ}$ ), cujos resultados poderiam levar à exclusão de famílias excedentes ou à restituição do cadastro aos municípios para sua adequação. Esse dado indica que, embora a CEF atuasse na operação do cadastro, a base de dados estava sob o poder do órgão gestor do programa. Mas isso também indica a autonomia de que dispunha o município em definir quais famílias seriam beneficiadas, bem como aquelas que seriam excluídas.

A Lei n. ${ }^{\circ}$ 10.219/2001, em seu formato geral, foi a confirmação da MP n. ${ }^{\circ}$ 2.140/2001, uma medida constitucionalmente necessária à manutenção de seus efeitos. ${ }^{26}$ Dados adicionais às suas disposições virão com o Decreto n..${ }^{\circ}$ 3.823, de 28 de maio de 2001 , que aprova o regulamento do Programa Bolsa Escola. Logo em seu primeiro artigo, esse Decreto define o valor do corte de renda para a seleção das famílias: $\mathrm{R}$ \$ 9o, oo de renda per capta. Note-se que há uma diferença importante em relação ao PETI, pois agora expõe-se um valor nominal e não "famílias com renda per capta de até I/2 salário mínimo" como previsto para aquele programa. (BRASIL, 2000) ${ }^{27}$ Em maio de 2001, quando foi publicado o Decreto nํㅜ 3.823, o salário mínimo era de $\mathrm{R} \$ 180,00,{ }^{28}$ logo, o parâmetro de $\mathrm{R} \$ 90,00$ per capta do Bolsa Escola equivalia a I/2 salário mínimo, mas a não citação desse critério de corte desvincula automaticamente (ou simplesmente não vincula) a transferência de renda desse programa da política salarial. Assim, um eventual reajuste no salário mínimo, por exemplo, não implicaria uma necessária ampliação do raio de cobertura do Bolsa Escola.

26 A Constituição Federal do Brasil, de 1988, prevê, em seu Art. 62, que "Em caso de relevância e urgência, o Presidente da República poderá adotar medidas provisórias, com força de lei, devendo submetê-las de imediato ao Congresso Nacional”. Assim, a Medida Provisória é um instrumento legal de prerrogativa do Poder Executivo, mas com validade precária, pelo que se submete ao crivo do Legislativo para sua conversão definitiva em lei.

27 Anexo, item 3.

28 Valor estipulado pela Medida Provisória n. ${ }^{2} 2.142$, de 29 de março de 2001. 
Através do Decreto (n. - 3.823/2001), foi criada, na estrutura do Ministério da Educação, uma instância específica para o acompanhamento do Programa, a Secretaria do Programa Nacional de Bolsa Escola. (BRASIL, 20o1d, Art. $3^{\circ}$ ) É a essa Secretaria que se remetem as competências referidas ao Ministério, como a agora explicitada de "organização e manutenção do Cadastro Nacional de Beneficiários” (BRASIL, 20o1d, Art. $3^{\circ}$, Parágrafo único, inciso III) e, ainda em relação ao cadastro, de realização de auditorias, o que indica uma verificação permanente da consistência dos dados. Não obstante, as atribuições da CEF foram reiteradas no Decreto. No âmbito municipal, a manutenção de um cadastro das famílias beneficiárias constitui-se numa das condições essenciais para a adesão ao programa (BRASIL, 20o1d, Art. $7^{\circ}$, inciso III), comprovado com a anexação de um extrato desse cadastro ao Termo de Adesão. (BRASIL, 20o1d, Art. $8^{\circ}$ ) Ou seja, o programa pressupõe a existência de um público vivendo nas condições socioeconômicas que estabelece como critérios, e que o município tem (ou deve ter) algum controle das informações sobre as características desse público.

Nesse Decreto, os termos "cadastro" e "cadastramento" são aparentemente usados de forma similar, como se vê, por exemplo, ao referir-se à "organização dos cadastros”, onde se afirma que "O cadastro de famílias beneficiárias, constituído pelos dados relativos às famílias e crianças atendidas pelo Programa Bolsa Escola, será elaborado pelo Poder Executivo Municipal”. (BRASIL, 2001d, Art. 12) Essa elaboração de responsabilidade do município desdobra-se no preenchimento de formulário específico em duas vias, uma para arquivamento municipal e outra para encaminhamento à CEF, para a inclusão no Cadastro Nacional. (BRASIL, 2001d, Art. 12, § 1ํㅡㄹ Em conjunto a isso, o município deve encaminhar extrato do cadastro à Secretaria Nacional do programa, para confirmação dos dados inseridos pela Caixa Econômica. (BRASIL, 2001d, Art. 12, § $2^{\circ}$ ) Ao que parece, pelo menos nessa fase inicial, não foi definido um modelo de formulário para ser utilizado no cadastramento das famílias, o que gera ambiguidades inerentes à ação e inconsistências na base de dados, considerando que cada município teria liberdade para elaborar o seu próprio formulário. Isso poderia redundar na inviabilização de um banco de dados nacional.

É importante destacar, mais uma vez, que o Cadastro Nacional de Beneficiários constitui-se na compilação dos dados das famílias beneficiárias, pois isso demonstra que o cadastramento era efetuado com o fito específi- 
co de implementar o Programa Bolsa Escola. Outro destaque importante é que, para constituir esse Cadastro, a CEF deveria

[...] efetuar o cruzamento dos dados pessoais dos responsáveis e das crianças a serem atendidas com as informações disponíveis nos cadastros do Programa de Integração Social (PIS), do Programa de Formação do Patrimônio do Servidor Público (PASEP), e do Contribuinte Individual (CI)"29 (BRASIL, 2001d, Art. 13, § 1º); o número localizado nesses registros servirá de "código de identificação" dos beneficiários. Ora, esse dado, comparado com aquele que diz respeito à desvinculação da elegibilidade para o programa da política salarial impõe uma incógnita, porque faz o caminho de volta, uma vez que o referencia aos registros do mercado de trabalho e da Previdência Social. Essa referência se acentua quando se delega à CEF mais uma tarefa: uma vez realizado o cruzamento e verificando-se a inexistência de registros, a identificação se daria mediante atribuição de um "Número de Identificação Social - NIS, gerado de acordo com os conceitos e critérios básicos utilizados para o cadastramento no [...] PIS. (BRASIL, 20o1d, Art. 13, § $2^{\circ}$ )

Ou seja, o NIS é criado como um equivalente desses registros anteriores.

Reitera-se no Regulamento que, para a concessão dos benefícios, a Secretaria Nacional do programa deverá compatibilizar os dados do Cadastro com as informações sobre indicadores sociais e econômicos do município (BRASIL, 2001d, Art. 14, inciso I), o que funciona, junto ao código de identificação e à instituição de um conselho de controle social, como um sistema de fiscalização sobre o processo de seleção de beneficiários, sem retirar, contudo, a autonomia da administração municipal nesse aspecto, atuando de forma mais efetiva, portanto, na limitação da cobertura. Mas, também, essa autonomia submete-se à fiscalização de outras instâncias, como se vê na exigibilidade de atualização anual do cadastro, cujos dados devem ser enviados pelos municípios à Secretaria Nacional durante o primeiro trimestre de cada ano (BRASIL, 20o1d, Art. 16), e pela realização de auditoria interna do programa por essa secretaria para averiguação de irregularidades. (BRASIL, 2001d, Art. 26)

Um novo regulamento do Programa foi editado em 24 de julho de 2002, Decreto 4.313, quando já vigoravam os critérios do Cadastro Único. Manteve-se, pois, a prerrogativa do município de selecionar as famílias beneficiá-

29 Tratar-se-á do PIS e PASEP mais à frente, numa discussão sobre o NIS, utilizado pelo Cadastro Único. 
rias, mas a partir das "famílias elegíveis" segundo o novo cadastro. Essa possibilidade de seleção direta dos beneficiários parece mesmo ter se mantido a despeito da implantação do Cadastro Único e de seus pretendidos critérios de impessoalidade, algo que se sugere na manutenção, nos moldes em que foi criada, da atribuição do "Conselho de Controle Social" - formado por representantes da administração municipal e da sociedade civil, com competência deliberativa - para "aprovar a relação de famílias selecionadas pelo Poder Executivo Municipal”. (BRASIL, 2002a, Art. 23, inciso III)

\section{BOLSA ALIMENTAÇÃO - PROGRAMA NACIONAL DE RENDA MÍNIMA VINCULADO À SAÚDE}

Ainda no ano de 2001, criou-se o Programa Bolsa Alimentação, através da Medida Provisória n. 2.206 , do dia 10 de agosto, com o objetivo de promover "condições de saúde e nutrição de gestantes, nutrizes e crianças de seis meses a seis anos e onze meses de idade, mediante a complementação da renda familiar para melhoria da alimentação". (BRASIL, 2001i, Art. $2^{\circ}$ ) Trata-se, como o PETI e o Bolsa Escola, de um programa de transferência monetária a famílias situadas numa faixa de renda estipulada pelo Estado. Pode-se considerar que a sua concepção segue no sentido de complementar os programas anteriores, seja pela sua vinculação à saúde - e não à educação-, seja pelas características definidas para a seleção de seus beneficiários: "gestantes" e "nutrizes", que até então não haviam tido atenção direta dos programas, e "crianças de seis meses a seis anos e onze meses de idade", um recorte imediatamente anterior ao estipulado para o PETI, por exemplo, que se iniciava aos sete anos. Note-se que, no Bolsa Alimentação, o critério de idade das crianças inicia-se em seis meses e não em zero, o que se justifica pela atenção às nutrizes, considerando um intervalo mínimo de seis meses para amamentação. A exceção é para o caso de crianças cuja genitora seja portadora de Human Immunodeficiency Virus - Síndrome da Imunodeficiência Adquirida - (HIV-AIDS), quando o benefício pode ser concedido

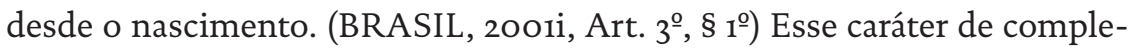
mentação aqui sugerido confirma-se quando se verifica que, para o cálculo da faixa de renda familiar, excetuam-se os rendimentos provenientes de programas federais (BRASIL, 2001i, Art. $3^{\circ}$, $\$$ ₹ $2^{\circ}$, inciso III), diferente do que anteriormente se previu para o Bolsa Escola em relação ao PETI. (BRASIL, 2001h, Art. $\left.7^{\circ}\right)$ 
O programa Bolsa Alimentação destinou-se a famílias com pessoas “em risco nutricional" (BRASIL, 20oii, Art. $3^{\circ}$ ), as quais fariam jus a um benefício mínimo de $\mathrm{R} \$ 15$, oo e máximo de $\mathrm{R} \$ 45$, oo, variando entre uma e três bolsas respectivamente (BRASIL, 2001i, Art. $4^{\circ}$ ) - com uma estrutura interna de alocação do benefício semelhante ao que se dava no Bolsa Escola. A responsabilidade pela coordenação, acompanhamento e avaliação do programa foi delegada ao Ministério da Saúde. Um dado importante diz respeito à relação entre os entes federativos: a implementação do programa se daria na relação direta da União com os municípios, contudo, em caso de descumprimento das suas disposições por parte do município, as atribuições deste passariam à esfera estadual. (BRASIL, 2001i, Art. 10) No dia seis de setembro do mesmo ano (2001), a Medida Provisória n.. 2.206/2001 foi reeditada sem alterações. (BRASIL, 2001i)

A regulamentação do Bolsa Alimentação veio com o Decreto n.. 3.934, de 20 de setembro de 2001. Nesse documento, a vigência dos benefícios foi definida em seis meses (BRASIL, 2001b, Art. $2^{\circ}$ ), passível de renovação mediante cumprimento de uma "agenda de compromissos" por parte das famílias beneficiárias, durante o período de concessão, o que correspondia à sua participação "em ações básicas de saúde, com enfoques predominantemente preventivos, tais como pré-natal, vacinação, acompanhamento do crescimento e desenvolvimento, incentivo ao aleitamento materno e atividades educativas em saúde". (BRASIL, 20orb, Art. $2^{\circ}$, $\$ 3^{\circ}$ ) Às responsabilidades atribuídas ao Ministério da Saúde, adicionou-se "o controle" sobre as atividades do programa no âmbito nacional (BRASIL, 2001b, Art. $3^{\circ}$ ), reiterando-se, porém, que a responsabilidade pela sua implantação e operação pertence ao município. (BRASIL, 2001b, Art. 5-ㅜ을 Em conta desse controle, os municípios deverão também manter sob sua guarda "Os cadastros e a documentação comprobatória” de suas informações por período não inferior a dez anos. (BRASIL, 2001b, Art. 10) Essa alusão aos cadastros aparece de forma muito superficial. Mesmo a CEF, que no Bolsa Escola operaria o cadastro, no Bolsa Alimentação aparece na condição apenas de "agente pagador” (BRASIL, 2001b, Art. 11), sem qualquer envolvimento nos procedimentos de seleção de beneficiários. Assim, ainda que responda pela regulamentação do programa, o Decreto $\mathrm{n}^{\mathrm{0}}$ 3.934/2001 deixa uma lacuna quanto às formas de inserção das famílias visadas no programa, inclusive pela não definição da faixa de renda familiar per capta que servirá de corte. 
Esse problema vai ser resolvido pelo Ministério da Saúde através da Portaria n. ${ }^{\circ}$ 1.770, com data idêntica à do Decreto, 20 de setembro, mas publicada três dias depois, em 24 de setembro de 2001. ${ }^{30}$ Em verdade, dada a limitação do Decreto, pode-se considerar que é essa Portaria que vai efetivamente regulamentar o programa Bolsa Alimentação. Nela, as famílias alvo do programa, além da condição de risco nutricional, situam-se numa faixa de renda de zero a meio salário mínimo per capta. Recomenda-se às secretarias municipais que se estabeleçam parcerias em favor da identificação das famílias em maior risco nutricional, e sugere-se que se busque, nesse sentido, a Pastoral da Criança, considerando a natureza e o grau de cobertura de suas atividades. (BRASIL, 20o1j, Art. $7^{\circ}$, Parágrafo único)

Quanto à agenda de compromissos adotada como contraparte das famílias, a Portaria n. ${ }^{\circ}$ 1.770/2001 vem discriminando o que cabe a cada beneficiário ou responsável:

I. gestantes:

a) fazer a inscrição no pré-natal e comparecer às consultas, de acordo com o preconizado pelo Ministério da Saúde;

b) participar de atividades educativas sobre aleitamento materno e orientação alimentar e nutricional da gestante;

II. nutrizes (mães de crianças com até seis meses de idade em aleitamento materno):

a) apresentar Registro de Nascimento da criança;

b) estar amamentando no momento da inscrição e manter a amamentação;

c) levar a criança às unidades de saúde para a realização do acompanhamento do crescimento e desenvolvimento, conforme preconizado pelo Ministério da Saúde;

d) cumprir o calendário vacinal da criança;

e) participar de atividades educativas sobre alimentação e nutrição da mãe, aleitamento materno e cuidados gerais com a saúde da criança.

III. responsáveis pelas crianças de seis meses a seis anos e 11 meses de idade:

a) apresentar Registro de Nascimento da criança;

b) cumprir o calendário vacinal e a suplementação com vitamina A nas áreas onde esta ação é preconizada;

30 O Decreto n. ${ }^{\circ}$ 3.934/2001 foi publicado em 21 de setembro de 2001. 
c) levar a criança às unidades de saúde para a realização do acompanhamento do crescimento e desenvolvimento, conforme preconizado pelo Ministério da Saúde;

d) participar de atividades educativas sobre a importância do aleitamento materno até os dois anos ou mais, cuidados gerais com alimentação e saúde da criança e desenvolvimento infantil.

O "processo de seleção, inscrição, renovação e desligamento dos beneficiários” (BRASIL, 2001j, Art. 6º, alíneas b) ficou sob a coordenação das secretarias municipais de saúde, às quais coube também, dentre outras atribuições, "implantar e manter atualizados os dados do Sistema de Informações do Programa Bolsa Alimentação" - SBA. (BRASIL, 2001j, Art. 6º, alíneas c) E aqui a esfera estadual foi também incluída, não apenas substituindo o município quando de sua falta no cumprimento das atribuições cabidas, mas assumindo um conjunto de atribuições próprias, dentre as quais se inclui "apoiar tecnicamente os municípios na implantação do Sistema de Informações do Programa Bolsa Alimentação”. (BRASIL, 2001j, Art. 8oa alínea d) Como nos programas anteriores, então, desenha-se também para o Bolsa Alimentação um sistema de informações sobre os beneficiários do programa, condição para a sua implementação. Esse Sistema deveria ser desenvolvido e mantido pelo Ministério da Saúde, o que se faria através do DATASUS, servindo-lhe nos processos de "implantação, controle, acompanhamento e avaliação operacional do Programa”. (BRASIL, 2001j, Art. 9º alínea f) Confirma-se, portanto, a lógica de cadastramento particular do público-alvo de cada programa, a despeito, inclusive, de já se haver concebido o Cadastro Único. 